\title{
THE
}

2006

\section{Internal Tides in the Southwestern Japan/East Sea}

Jae-Hun Park

University of Rhode Island

D. Randolph Watts

University of Rhode Island

Follow this and additional works at: https://digitalcommons.uri.edu/gsofacpubs

\section{Citation/Publisher Attribution}

Park, J., \& Watts, D. R. (2006). Internal Tides in the Southwestern Japan/East Sea. J. Phys. Oceanogr., 36, 22-34. doi: 10.1175/JPO2846.1

Available at: https://doi.org/10.1175/JP02846.1

This Article is brought to you for free and open access by the Graduate School of Oceanography at DigitalCommons@URI. It has been accepted for inclusion in Graduate School of Oceanography Faculty Publications by an authorized administrator of DigitalCommons@URI. For more information, please contact digitalcommons-group@uri.edu. 


\title{
Internal Tides in the Southwestern Japan/East Sea
}

\author{
JAe-Hun PARK AND D. RANDOLPh Watts \\ Graduate School of Oceanography, University of Rhode Island, Narragansett, Rhode Island
}

(Manuscript received 22 June 2004, in final form 29 June 2005)

\begin{abstract}
This paper investigates the internal tidal energy distribution in the southwestern Japan/East Sea using vertical round-trip travel time $(\tau)$ data from 23 pressure-sensor-equipped inverted echo sounders (PIES). The $\tau$ records are analyzed by bandpass filtering to separate time-dependent variability of the semidiurnal and diurnal bands. The semidiurnal internal tides exhibit a horizontal beam pattern of high energy, propagating into the open basin. They originate from a restricted portion of the shelf break where the Korea Strait enters the Ulleung Basin. The generation appears to occur at $\sim 200-\mathrm{m}$ water depth near $35.5^{\circ}-35.7^{\circ} \mathrm{N}$ and $130^{\circ}-131^{\circ} \mathrm{E}$, where the slope of bottom topography matches that of the wave characteristics, coinciding with the location where the semidiurnal barotropic cross-slope tidal currents are strongest. Maximum vertical displacement of the thermocline interpreted as a long-wave first baroclinic mode from the measured $\tau$ is about $25 \mathrm{~m}$ near the generation region. Annual and monthly variations of the propagation patterns and generation energy levels are observed, and these are closely associated with changes in the mesoscale circulation and stratification. Eastward (westward) refraction is observed when a warm (cold) eddy crosses the path of internal tide propagation. Moreover, when the generation region is invaded by cold eddies that spoil the match between shelf break and thermocline depth, the internal tidal energy level decreases by a factor of about 2. A simple geometric optics model is proposed to explain the observed horizontal refraction of the beam of semidiurnal internal tides in which stratification and current shear play essential roles. In contrast, diurnal internal tides are observed to be trapped along the continental slope region around $36^{\circ} \mathrm{N}$.
\end{abstract}

\section{Introduction}

The Japan/East Sea (JES) is a semi-enclosed basin located between Korea, Japan, and Russia (Fig. 1). It has a maximum depth of about $3700 \mathrm{~m}$ and connects with the North Pacific Ocean through three straits, all with sill depths shallower than $150 \mathrm{~m}$. The warm Pacific water enters into the JES through the Korea Strait as the Tsushima Warm Current. After passing the strait, this inflow splits into two or three branches: one, called the East Korean Warm Current (EKWC), flows northward along the Korean coast and another, called the Offshore Branch, flows east-northeastward along the Japanese outer shelf. Cold freshwater flows southward from the northern JES along the east coast of Korea in the North Korean Cold Current, meeting the EKWC around $38^{\circ}-40^{\circ} \mathrm{N}$. At the confluence, the two currents turn east and leave the coast to form the subpolar front (SPF).

Corresponding author address: Jae-Hun Park, Graduate School of Oceanography, University of Rhode Island, Narragansett, RI 02882-1197.

E-mail: jpark@gso.uri.edu
Recently, Mitchell et al. (2005a) presented mesoscale circulation patterns, including evolution and propagation of the Ulleung Warm Eddy (UWE) and the Dok Cold Eddy (DCE) in the southwestern JES, which is called the Ulleung Basin (UB). They used temperature maps at 100-m depth that were obtained from an array of 23 pressure-sensor-equipped inverted echo sounders (PIES). The PIES measures bottom pressure $\left(P_{\text {bot }}\right)$ and round-trip acoustic travel time $(\tau)$ from bottom to surface, which together determine barotropic and baroclinic variations of the water column above the PIES. The PIES experiment in the UB was originally designed to investigate mesoscale ocean circulation variability. For that purpose, 5-day low-pass filtering was initially applied to the hourly $P_{\text {bot }}$ and $\tau$ records to focus upon geostrophic signals. However, the PIES data are also useful for the study of shorter-time-scale $(<1.5$ days) phenomena such as barotropic and baroclinic tides, for which we use the hourly $P_{\text {bot }}$ and $\tau$ records prior to low-pass filtering. Some $\tau$ records collected near the continental slope of the UB showed relatively high spectral energy in the semidiurnal and diurnal frequency bands. Barotropic tidal amplitudes at these fre- 


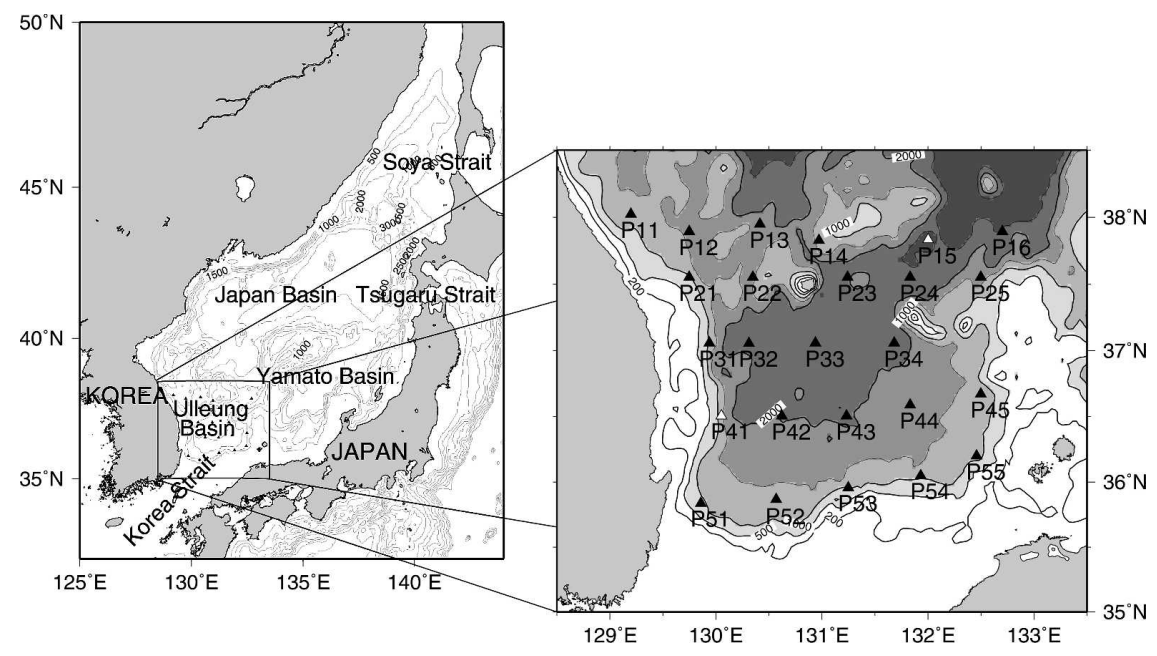

FIG. 1. The Japan/East Sea. Solid triangles indicate PIES, and bathymetry contours are in meters. Open triangles indicate PIES sites at which an instrument was lost or few data were obtained. The site identification numbers (Pnn) are shown.

quencies are about $0.05 \mathrm{~m}$, and the associated variations in $\tau(\sim 70 \mu \mathrm{s})$ are very small relative to variations due to internal tides that we observe in this region (nevertheless we removed them exactly from $\tau$ using $P_{\text {bot }}$ measurements).

Internal tides are caused by the interaction of the barotropic tide with bottom topography generating internal waves of tidal frequency (e.g., Wunsch 1975). Internal tide models show that the generation process is largest where the slope of the bathymetry $(s)$ matches the internal wave characteristic slope (e.g., Baines 1982), defined as

$$
\gamma= \pm\left[\frac{\omega^{2}-f^{2}}{N^{2}(z)-\omega^{2}}\right]^{1 / 2},
$$

where $\omega$ is the wave frequency, $f$ is the inertial frequency, $N$ is the buoyancy frequency, and $z$ is the vertical coordinate. The internal wave energy propagates along the ray paths represented by the characteristics $\gamma$. Propagating internal waves exist when $f<\omega<N(z)$ from Eq. (1). In contrast, if the internal wave period is larger than the inertial period, the internal wave will be trapped around the generation region.

Watts and Rossby (1977) showed that $\tau$ is insensitive to all but the lowest baroclinic mode vertical structure. They also showed that $\tau$ variations are mainly influenced by displacements of the main thermocline. Cartwright (1982) demonstrated internal tides may be studied from $\tau$ measurements if the surface tides are accurately known, for example from $P_{\text {bot }}$. Recently, $\tau$ was used to examine the time-varying characteristics of internal tides at the $M_{2}$ frequency near the Hawaiian
Ridge (Mitchum and Chiswell 2000; Chiswell 2002). Chiswell (2002) confirmed that $\tau$ measures the amplitude of the first baroclinic mode well, even in the presence of higher vertical-mode signals.

Little attention has been drawn to the tides in the JES, including the internal tides, because of the small tidal amplitude except within the Korea and Tatar Straits. Lie et al. (1992) reported on the semidiurnal internal tides from a 2-month thermistor chain mooring near $37^{\circ} \mathrm{N}$ off the east coast of Korea. They showed the amplitude of internal tides was on the order of $10 \mathrm{~m}$. However, their mooring site was just $1.5 \mathrm{~km}$ away from the coast and its depth was about $27 \mathrm{~m}$. Isoda and Murayama (1993) reported first-mode coastal-trapped waves with diurnal period from two current meters moored for one-and-one-half months at the continental shelf and shelf break along $132^{\circ} \mathrm{E}$ off the Japanese coast. They showed the waves were generated by the barotropic diurnal tidal oscillations on the shelf break and trapped there because $\omega<f$.

Until now, most internal tide studies from observations have focused on two-dimensional propagation of waves in $(x, z)$ space, where the $x$ axis is along the propagation direction. Usually, variations along the $y$ axis, across the propagation direction, have been neglected. However, horizontal internal tidal energy fields may be modulated significantly through interactions with mesoscale structures such as eddies and fronts. Although there are several theoretical investigations regarding how horizontal inhomogeneities modulate the internal wave field (e.g., Miropol'sky 2001), no comprehensive observational studies about this have been reported. 
In this paper, we will investigate the internal tides in the semidiurnal and diurnal frequency bands using the $\tau$ data measured by the PIES in the UB. The PIES sites were well situated to observe spatial variations of the internal tide fields for $2 \mathrm{yr}$. The $\tau$ records are analyzed with a bandpass filter (Butterworth) to test for temporal changes of internal tidal amplitude. We construct the horizontal maps of internal tidal energy distribution using the bandpass-filtered results and compare these maps with the mesoscale circulation patterns, thus revealing interactions between the semidiurnal internal tides and mesoscale circulation patterns. These observations provide a new perspective on how a beam of internal tides can be generated and refracted in horizontal two-dimensional space.

\section{Data and methods}

An array of 25 PIES, having 55-60 km spacing to cover all of the UB, was deployed from June 1999 to July 2001. Figure 1 shows their location and gives their identification numbers. The PIES measured hourly $\tau$ with 0.05 -ms accuracy and hourly $P_{\text {bot }}$ with better-than1-mm resolution. Two PIESs at P32 and P41 were lost because of deep crab-fishing activity, and P15 only measured $\tau$ for 2 months. Fortunately, the PIES at P32 was discovered by a Korean fisherman more than $2 \mathrm{yr}$ after the recovery cruise and both $\tau$ and $P_{\text {bot }}$ data at P32 were recovered successfully. Thus, we use 23 datasets of hourly $\tau$ and $P_{\text {bot }}$ in this study. Every dataset has 17712 values from 0100 UTC 16 June 1999 to 0000 UTC 23 June 2001. More details of the moorings and data processing are given in Mitchell et al. (2005a).

The $\tau$ records provide proxy estimates of the vertical profiles of temperature $(T)$, salinity $(S)$, and specific volume anomaly $(\delta)$ (Watts et al. 2001). In the JES, seasonal variations extend throughout the shallow thermocline waters. In contrast with other regions where a gravest empirical mode (GEM) technique can estimate vertical profiles of $T, S$, and $\delta$ from $\tau$, in the JES a simple GEM cannot distinguish between seasonal and mesoscale circulation variations. Therefore, Park et al. (2005) applied a new approach to estimate the vertical profiles from multi-index lookup tables as a function of $\tau$, sea surface temperature (SST), and pressure, referred to as the MI-GEM (Park et al. 2005). We estimate three-dimensional daily time series of $T, S$, and $\delta$ fields in the UB for $2 \mathrm{yr}$ using the MI-GEM technique.

We examine the circulation patterns in the UB by mapping the depth of the $5^{\circ} \mathrm{C}$ isotherm, $Z_{5}$, instead of the temperature at $100 \mathrm{~m}, T_{100}$, as had been done by Mitchell et al. (2005a). The $T_{100}$ maps may misrepresent the intermediate layer structures within the deeper thermocline, such as those caused by intrathermocline eddies (Gordon et al. 2002). The isotherm $Z_{5}$ is preferred for our purposes, because it represents the boundary between surface water and intermediate water in the UB (e.g., Kim et al. 1991). The time series of $Z_{5}$ reveal not only the mesoscale circulation patterns but also changes in stratification during the $2 \mathrm{yr}$.

We correct the effect of free surface displacement $(\eta)$ of barotropic tides on the $\tau$ data, using the $P_{\mathrm{bot}}$ data. The pathlength of sound propagation varies with $\eta$, which changes $\tau$ by $2 \eta / c$, with sound speed $c$ assumed to be $1505 \mathrm{~m} \mathrm{~s}^{-1}$. We determined the barotropic semidiurnal and diurnal tides from the $P_{\mathrm{bot}}$ data using the response analysis method (Munk and Cartwright 1966). The estimated tidal fluctuations of $\eta$ were converted to acoustic round-trip travel time and subtracted from $\tau$. In this study, we use the barotropic-tide-corrected $\tau$ records, which retain variations associated with internal tides.

We carry out a filtering procedure to extract the oscillating variabilities of $\tau$ at semidiurnal and diurnal frequency bands. We use a third-order bandpass Butterworth filter with cutoffs at 11.50 and $12.92 \mathrm{~h}$ for the semidiurnal frequency band and at 23.00 and $26.80 \mathrm{~h}$ for the diurnal frequency band. The filtering is carried out in the forward direction, and then the filtered sequence is reversed and run again through the filter in order to eliminate all phase shifts.

\section{Interpretation of $\tau$ fluctuations from first baroclinic mode}

The propagation equation for linear internal waves (e.g., Munk 1981) is

$$
\frac{d^{2} \zeta}{d z^{2}}+\left(\frac{\omega}{C}\right)^{2}\left[\frac{N^{2}(z)-\omega^{2}}{\omega^{2}-f^{2}}\right] \zeta=0,
$$

where $\zeta=\zeta(z) e^{i(k x-\omega t)}$ represents the vertical displacement, and $C$ is the horizontal propagation speed of internal waves. Numerical solutions of Eq. (2) for the semidiurnal internal tides are obtained by solving the vertical-mode eigenvalue problem with $N(z)$ calculated from the $T$ and $S$ profiles, for the $M_{2}$ tidal frequency $\omega$ $=1.405 \times 10^{-4} \mathrm{~s}^{-1}$, and with boundary conditions $\zeta=$ 0 at $z=0$ and $z=-H$, where $H$ is the water depth. We consider only the first baroclinic mode to estimate the vertical displacement from $\tau$, choosing to focus upon the first baroclinic mode because it typically has significant internal tidal energy. Our measurements are well suited for this study because $\tau$ is sensitive to predominantly the first baroclinic mode (Watts and Rossby 
1977). We assume for simplicity that density from 500 dbar to the bottom is homogeneous because the MIGEM technique estimates profiles only down to 500 dbar (Park et al. 2005), and the deeper stratification of the JES is very weak (Kim et al. 1991).

If we now assume that the variations in $Z_{5}$ and $\tau$ are solely due to first-baroclinic-mode amplitude changes, we can derive a simple relationship between variations in $Z_{5}$ and variations in $\tau$. Given any basic-state profile $T_{0}(z)$ and $S_{0}(z)$ in water depth $H$, and the first baroclinic mode $\zeta_{1}(z)$, which is normalized to have maximum amplitude of $1 \mathrm{~m}$, the perturbation of $\tau, \tau^{\prime}$, may be calculated as the difference

$$
\begin{aligned}
\tau^{\prime}= & 2\left\{\int_{-H}^{0} \frac{d z}{C\left[S_{0}\left(z+m \zeta_{1}\right), T_{0}\left(z+m \zeta_{1}\right), z\right]}\right. \\
& \left.-\int_{-H}^{0} \frac{d z}{C\left[S_{0}(z), T_{0}(z), z\right]}\right\} .
\end{aligned}
$$

Here $\tau^{\prime}$ varies linearly with small amplitude vertical displacements, so we can solve for the multiplicative amplitude $m$ that would be required to change $\tau$ by $\tau^{\prime}$. We define $\eta_{5}$ to be the perturbation displacement of $Z_{5}$ for $\zeta_{1}$, and hence $\eta_{5}=m \times \zeta\left(z=Z_{5}\right)$. For example, the $\eta_{5}$, induced by 0.5 -ms $\tau$ change, is plotted in Fig. 2 for the UB, using the real topography $H(x, y)$ from 2-min-resolution Global Seafloor topography data (Smith and Sandwell 1997) and the 2-yr mean stratification that we observed, $S_{0}(x, y, z)$ and $T_{0}(x, y, z)$. The maximum $\eta_{5}$ is shown near the North Korean Cold Current region (northwestern corner of the domain) since the cold upper layer at this region needs more vertical movement to effect a 0.5 -ms $\tau$ change. The rms of $\eta_{5}$ all over the UB is $12.0 \mathrm{~m}$. We convert the monthly rms and annual rms $\tau$ fluctuations into $\eta_{5}$ fluctuations using the first baroclinic mode in the following section.

\section{Results}

\section{a. Bandpass-filtering results}

Figure 3 exhibits examples of bandpass-filtering analysis results for sites P22, P24, P31, P33, P42, P52, and P53 (see inset Fig. 3) for the semidiurnal frequency band. First notice how different most of the records are from each other and from the barotropic tides (exemplified in the bottom panel). The bandpass-filtered results of P22 and P24 and those of P31 and P33 show no similarity, though each pair is located at the same latitude. However, almost every event at P42 exhibits significant correspondence to that at P52 in time and en-

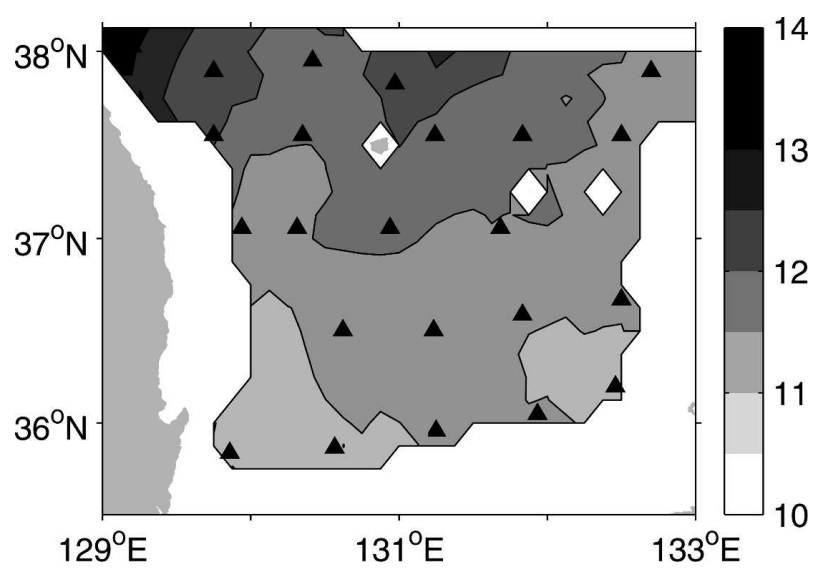

FIG. 2. Vertical displacement increase of $Z_{5}(\mathrm{~m})$ caused by 0.5 ms change of $\tau$, using the first baroclinic mode at the semidiurnal frequency. Solid triangles indicate PIES sites. Three white diamonds indicate Ulleung Island, Dok Island, and a seamount, from west to east, respectively.

velope shape. Some events at P33 correspond to those at $\mathrm{P} 42$ and $\mathrm{P} 52$.

The strongest internal tidal energy occurs at site P52 and has maximum fluctuation of $1.12 \mathrm{~ms}\left(\sim 25-\mathrm{m} \eta_{5}\right)$ during the 200 days. The $\tau$ records at P31 and P53 exhibit less semidiurnal variability than the other records, with internal tides at $\mathrm{P} 31$ being largest during an interval when they are smallest at P33.

P53, although located close to P52 ( $60-\mathrm{km}$ distance), reveals additional lower-frequency fluctuations. Therefore, we also ran bandpass filtering on $\tau$ at P53 for the diurnal frequency band, as exhibited in Fig. 3. For comparison, the barotropic tidal variation in $P_{\text {bot }}$ at P53 is shown. Clearly, the internal tides at site P53 are dominated by diurnal fluctuations (rather than semidiurnal), and these may be strongly related to the barotropic tides, as we discuss in section $4 \mathrm{~d}$.

\section{b. Background fields}

During the period from June 1999 to June 2001, the UB showed five characteristic circulation patterns in the upper ocean (Mitchell et al. 2005a). The pattern changes were associated with the size, shape, and position of the UWE, generation and propagation of the DCE, strengthening and weakening of the East Korean Warm Current and the Offshore Branch, and northward and southward migration of the SPF. Mitchell et al. (2005a) demonstrated that those pattern changes were associated with volume transport variations of the Korea Strait during the $2 \mathrm{yr}$. Yearly mean $Z_{5}$ maps in the upper panels of Fig. 4 illustrate the annual circulation pattern during each year. During year 1 (June 1999-June 2000) of the PIES deployment, 

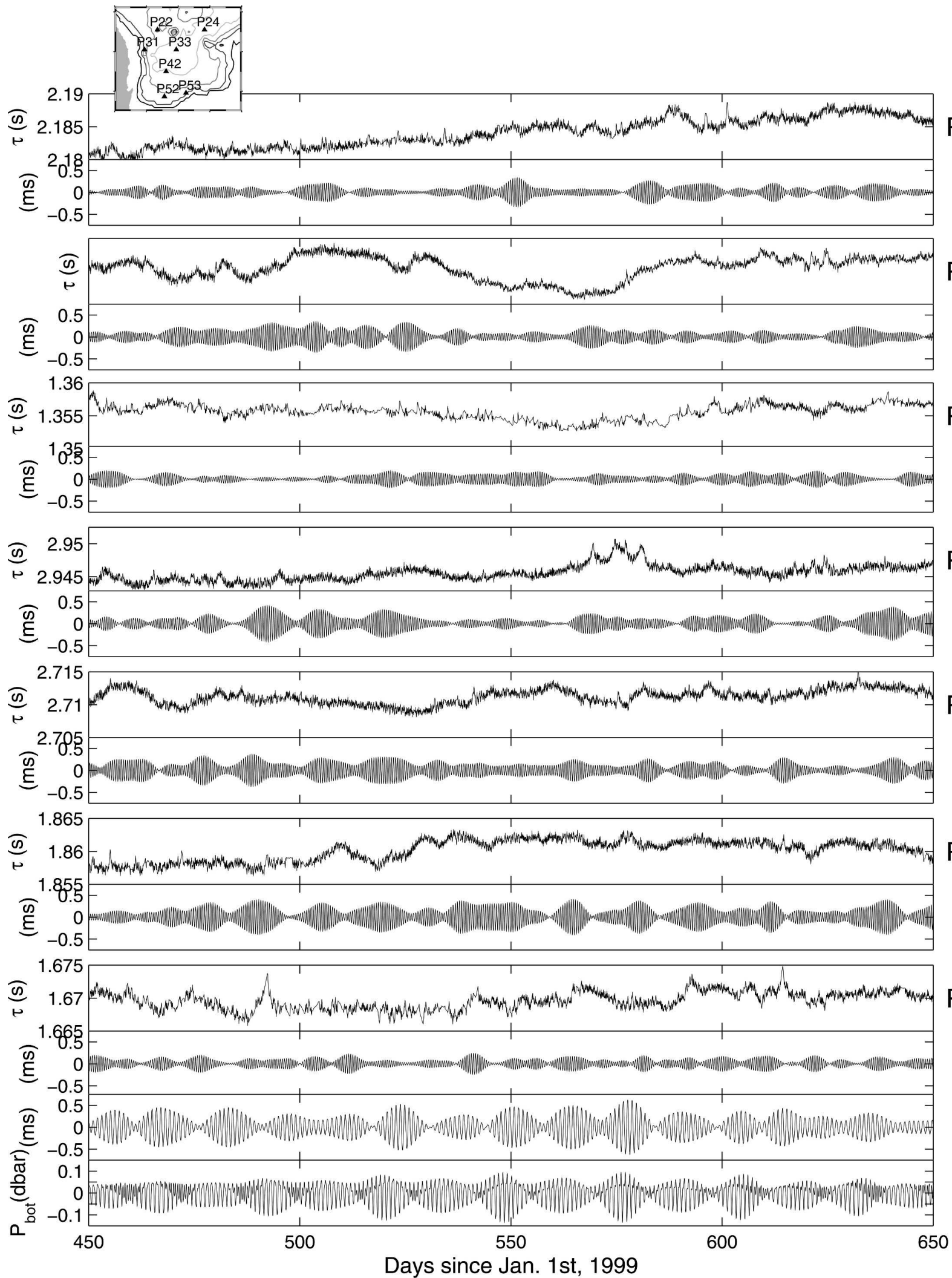

FIG. 3. Time series of round-trip travel time $(\tau)$ and their bandpass-filtered results with semidiurnal passband between 11.50 and 12.92 h for P22, P24, P31, P33, P42, P52, and P53 PIES sites (see inset at upper left). Bottom two panels of P53 show additionally the bandpass-filtered results on $\tau$ with diurnal passband between 23 and $26.8 \mathrm{~h}$ and the tidal component of the $P_{\text {bot }}$ record. 

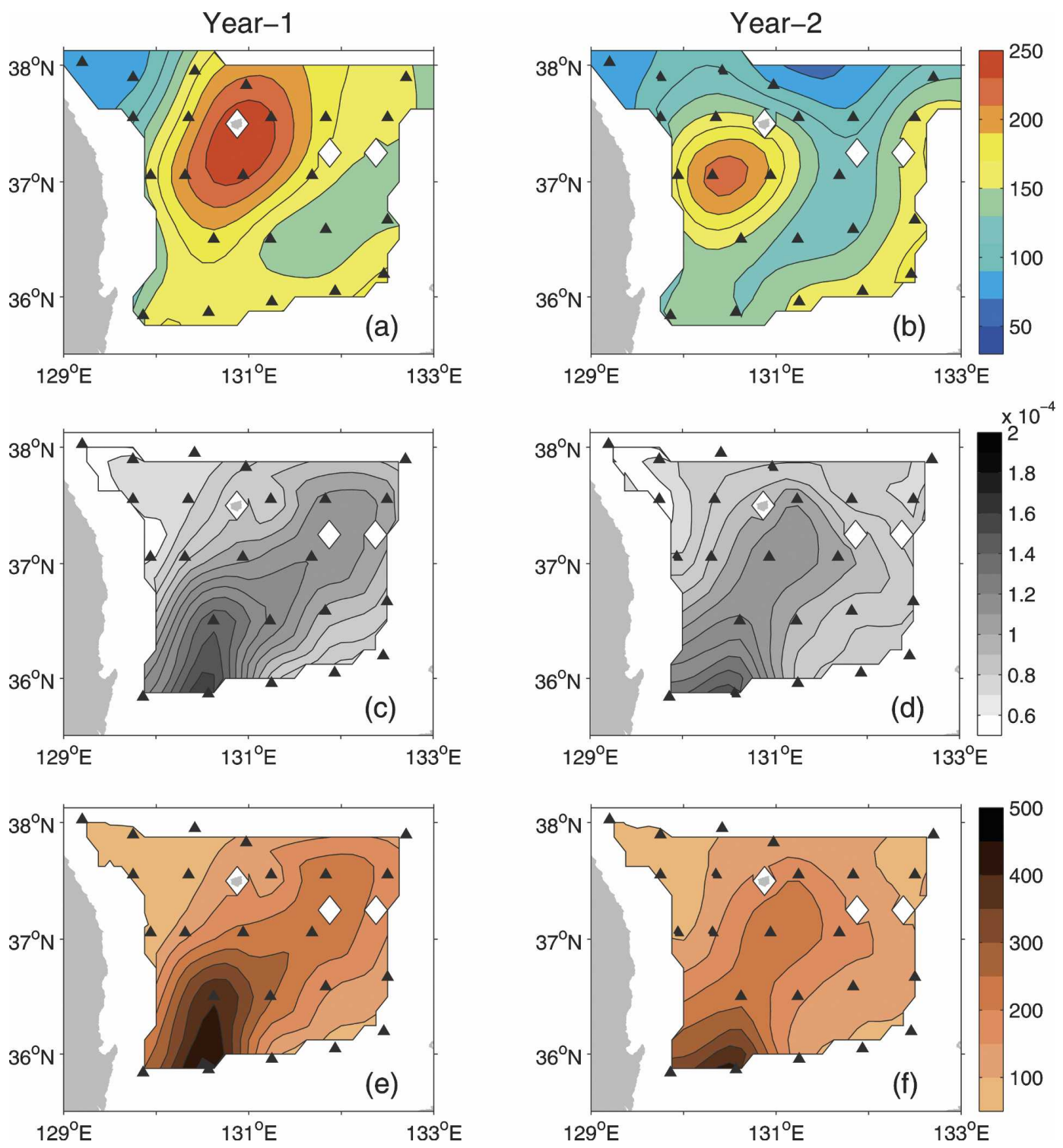

FIG. 4. Yearly mean maps of $5^{\circ} \mathrm{C}$ depth $\left(Z_{5}, \mathrm{~m}\right)$ during (a) year 1 (June 1999-June 2000) and (b) year 2 (June 2000-June 2001) (contour interval $20 \mathrm{~m}$ ). The path of the SPF is approximately indicated by the $100-\mathrm{m}$ contour. Yearly mean maps of the rms amplitude of bandpass-filtered $\tau(\mathrm{s})$ at the semidiurnal frequency band during (c) year 1 and (d) year 2 (contour interval $10^{-5} \mathrm{~s}$ ). Yearly mean maps of rms semidiurnal internal tidal energy $\left(E_{p} ; \mathrm{J} \mathrm{m}^{-2}\right)$ during (e) year 1 and (f) year 2 (contour interval $50 \mathrm{~J} \mathrm{~m}^{-2}$ ). Solid triangles indicate PIES sites.

the UWE is strongly developed and $Z_{5}$ near the eddy core is nearly $250 \mathrm{~m}$. The UWE is elongated on a northsouth axis, and the minor axis of the UWE is about 150 $\mathrm{km}$. The SPF occurs only in the northwestern part near $38^{\circ} \mathrm{N}, 130^{\circ} \mathrm{E}$. During year 2 (June 2000-June 2001), the UWE shrinks to a circular shape with diameter about $100 \mathrm{~km}$, and the $Z_{5}$ at the UWE core is about $200 \mathrm{~m}$. The SPF has shifted south of $38^{\circ} \mathrm{N}$, meandering across the northern observational domain. The East Korean Warm Current is weakened, and the Offshore Branch is strengthened during year 2. Overall, the basin is warmer in year 1 than in year 2 .

\section{c. Semidiurnal internal tides-Temporal and spatial variability}

For each year, the rms amplitudes of the bandpassfiltered results of $\tau$ in the semidiurnal frequency band are mapped in the middle panels of Fig. 4. As shown in the lower panels of Fig. 4, the corresponding estimates of potential internal tidal energy $E_{p}$ are computed us- 
ing the first-baroclinic-mode amplitudes by (Gill 1982; Dushaw et al. 1995)

$$
E_{p}=\frac{1}{2} \int_{-H}^{0} \rho(z) N^{2}(z)\left[m \zeta_{1}(z)\right]^{2} d z
$$

The yearly mean maps for both years illustrate a horizontal beamlike distribution of internal tidal energy, suggesting that the semidiurnal internal tides are generated at the shelf-slope region in the western half of the Korea Strait and propagate into the open basin. The beam refracts eastward starting near $36.5^{\circ} \mathrm{N}$ in the year-1 map, and it propagates straighter in the year-2 map.

The case studies in this section illustrate that the horizontal distributions of internal tidal energy in the UB are altered by the mesoscale circulation pattern, in particular by the strength and position of the UWE. Even for annual means, Fig. 4 indicates more significant refraction during year 1 when the beam encounters a strongly developed UWE in the mean.

Figure 4 also illustrates that semidiurnal internal tidal energy in year 1 is stronger than that in year 2, and hence the $\mathrm{rms} E_{p}$ near the generation region during year $1\left(463 \mathrm{~J} \mathrm{~m}^{-2}\right)$ is larger than that during year $2(415$ $\mathrm{J} \mathrm{m}^{-2}$ ). The beam widths are approximately the same in the two years, and the energy decrease due to beam spreading is approximately the same (twofold in 200 $\mathrm{km}$ ) in each year. However, because of the refraction, the internal tidal energy near Dok Island $\left(37.25^{\circ} \mathrm{N}\right.$, $131.88^{\circ} \mathrm{E}$ ), for example, changes by nearly a factor of 2 between the years.

For more insight into the interactions between the internal tides and mesoscale circulation pattern, lunarmonthly (29.5 days) means of the circulation (indicated by mean $5^{\circ} \mathrm{C}$ isotherm depth $Z_{5}$ ) will next be compared with maps of the rms variations $\eta_{5}$ for the semidiurnal frequency band. We choose to average over a lunar month in order to avoid being aliased by modulation from spring-tide and neap-tide variations.

\section{1) CAse I: Beam Refracts eastward as the UWE DEVELOPS}

The top two rows of panels (days 166.5-284.5) in Fig. 5 show four successive months during which the UWE develops, starting with weak structure in the mean map for days 166.5-196. The UWE develops during the next two lunar months around $36^{\circ}-37^{\circ} \mathrm{N}$ and $130^{\circ}-131^{\circ} \mathrm{E}$, fed by a northward loop of warm current from the Korea Strait, as discussed in Mitchell et al. (2005a). The UWE grows strongest in the 255-284.5-day map and starts to merge with a warm eddy to its north, whose southern part is located near $38^{\circ} \mathrm{N}$ in all four lunar months.

The semidiurnal internal tide beam in the $\eta_{5}$ maps appears to exhibit refraction by this mesoscale circulation. In the first-lunar-month map, the internal tides propagate in a straight beam northward through the weak eddy field. The beam of internal tides appears to refract during days 196-225.5, and during the next two lunar months refracts farther eastward, as the internal tides encounter the UWE. The monthly average $Z_{5}$ and $\eta_{5}$ maps strongly suggest that the UWE located in the path of the propagating internal tides causes the eastward refraction, although the refraction in the last two panels is stronger than might be expected from the observed eddy structures. The $\eta_{5}$ maps show strong internal tidal energy near the generation region, and $Z_{5}$ remains $\sim 170 \mathrm{~m}$ near the generation region during the four lunar months.

\section{2) CAse II: BeAm Refracts westward by the DCE}

The middle two rows of panels (days 314-432) in Fig. 5 show a strongly developed UWE, centered near $37.5^{\circ} \mathrm{N}, 131^{\circ} \mathrm{E}$ with about $200-\mathrm{km}$ diameter. South of this a cold eddy, the DCE, propagates westward across latitude $36.5^{\circ} \mathrm{N}$ during these four lunar months.

During these months, the internal tide beam appears to refract successively eastward, nearly straight, westward, and then eastward again. The refraction is apparently related to the passage of the DCE, as follows: In the first month (days 314-343.5) when the cold eddy is to the east of the beam, the internal tides refract toward this cold region. In the second month (days 343.5-373) when the cold eddy is centered on the beam, the beam passes nearly straight north to $37^{\circ} \mathrm{N}$. When this beam encounters the UWE, it refracts eastward as in the previous case. In the third month (days 373-402.5) when the cold eddy has propagated to the west of the beam, the internal tides refract westward again toward the cold region. In the fourth month (days 402.5-432) the beam from $35.5^{\circ}$ to $37^{\circ} \mathrm{N}$ initially passes straight through relatively weak and symmetric east-west gradients of $Z_{5}$ and when it encounters the strong UWE it refracts eastward. It is interesting to note that at locations like $\left(37.5^{\circ} \mathrm{N}, 132.5^{\circ} \mathrm{E}\right)$ or along the shelf break off Korea, internal tide amplitude $\eta_{5}$ varies by a factor of 2 from one lunar month to another in response to this refraction.

\section{3) CASE III: BeAm WeAKens When COLD EDDY HITS THE SHELF BREAK}

The bottom two rows of panels (days 520.5-638.5) in Fig. 5 show four lunar months in which the UWE weak- 
(a) Case I

days 166.5 - 196
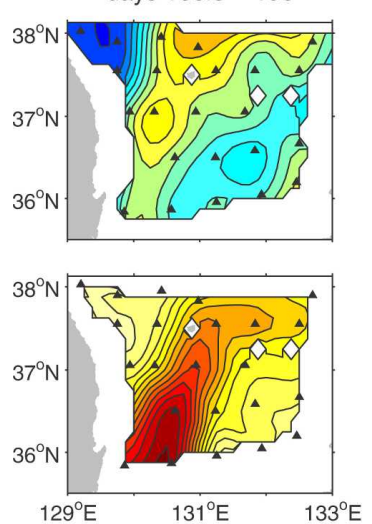

days $196-225.5$
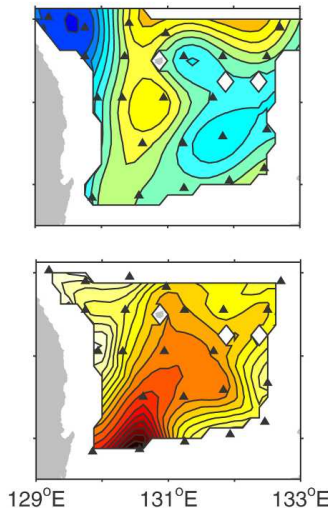

days $225.5-255$
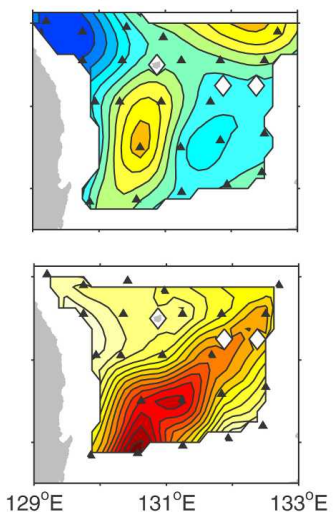

days $255-284.5$
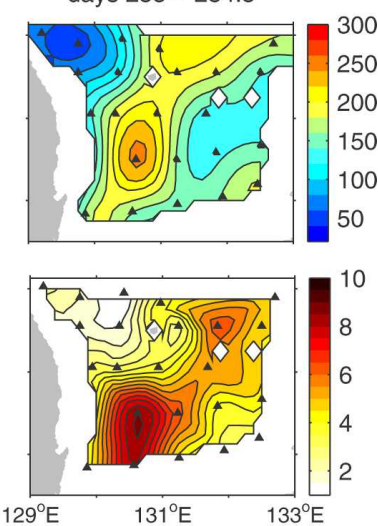

(b) Case II

days $314-343.5$

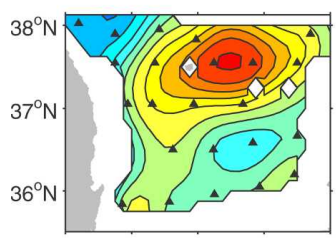

days $343.5-373$
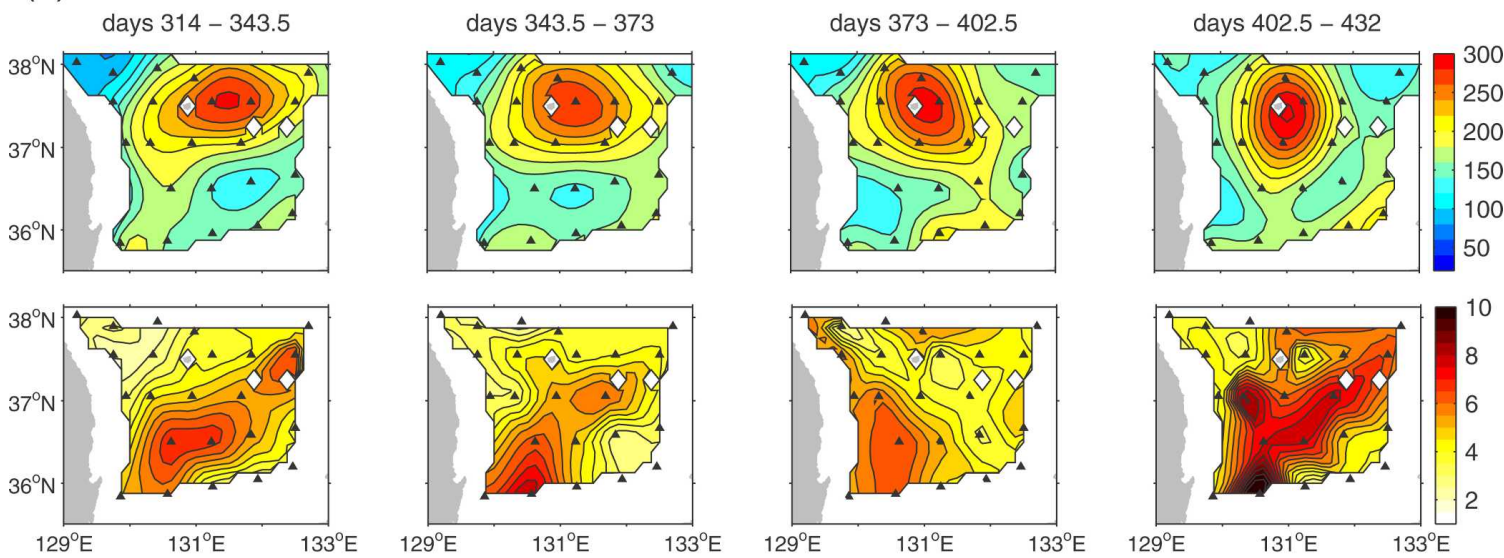

(c) Case III
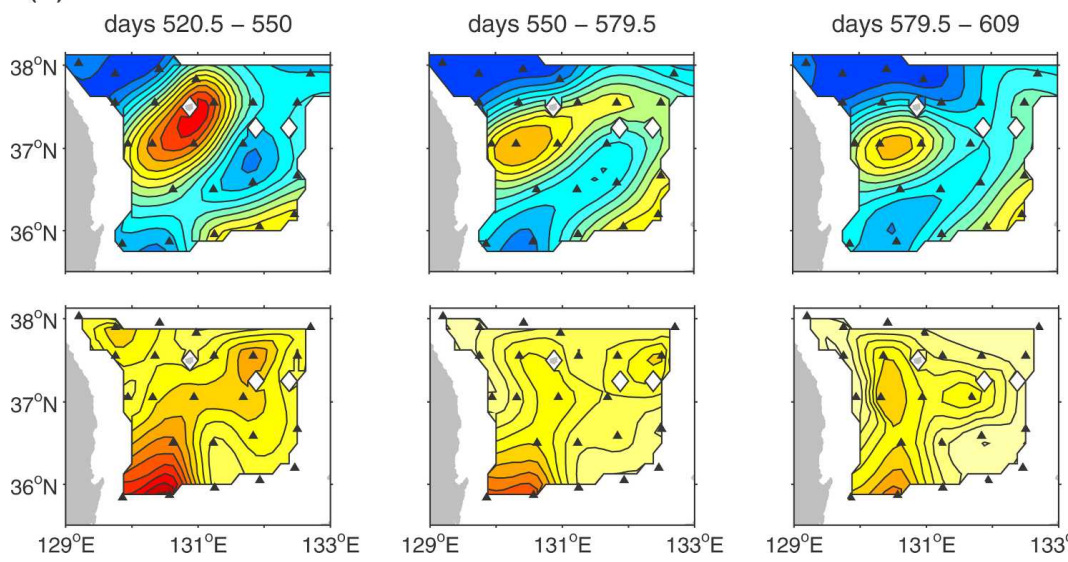
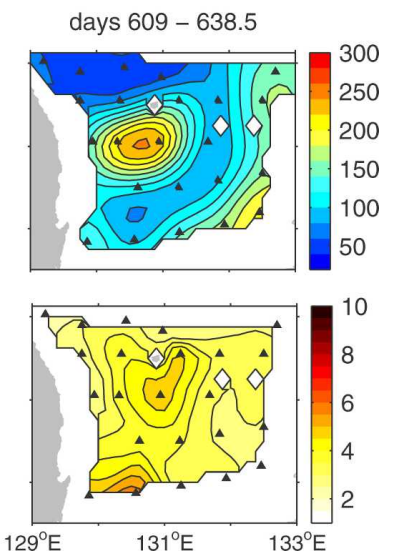

FIG. 5. Lunar monthly maps of mean $5^{\circ} \mathrm{C}$ depth $\left(Z_{5}\right)$ and rms semidiurnal internal tide amplitude $\left(\eta_{5}\right)$ during days (a) 166.5-284.5, (b) 314-432, and (c) 520.5-638.5. Contour intervals are 20 and $0.5 \mathrm{~m}$ for $Z_{5}$ and $\eta_{5}$ maps, respectively. Dates are days since 0000 UTC 1 Jan 1999. Solid triangles indicate PIES sites.

ens and shrinks while its center shifts southwest to $37^{\circ} \mathrm{N}, 130.5^{\circ} \mathrm{E}$. The DCE is formed from a deep trough of the SPF and intrudes southward during these months. At the southeast coast of Korea $\left(36^{\circ} \mathrm{N}, 130^{\circ} \mathrm{E}\right)$, coastal upwelling, as is typical of summertime (e.g., Lee et al. 1998), occurs during days 520.5-550, prior to arrival of the DCE. The inflow from the Korea Strait diverts offshore, cutting off the EKWC during these 4 

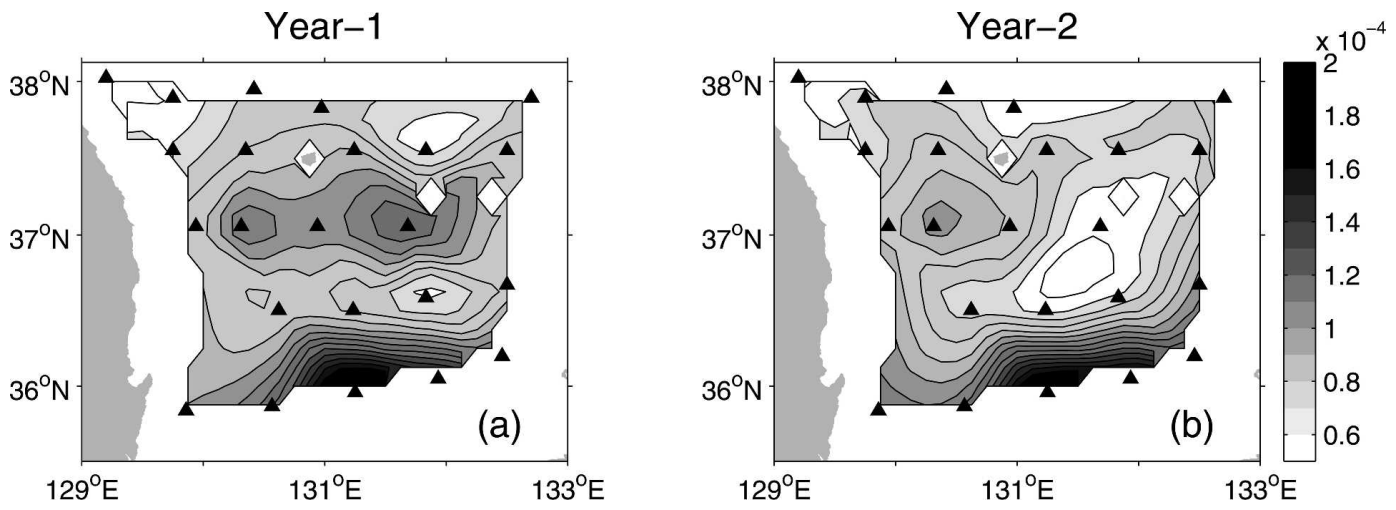

FIG. 6. Yearly mean maps of the rms amplitude of bandpass-filtered $\tau$ for the diurnal frequency band during (a) year 1 and (b) year 2. Contour interval as in Figs. 4c,d. Solid triangles indicate PIES sites.

months as shown in the $Z_{5}$ maps. The UWE shrinks in response, and a cold trough of the SPF protrudes southwestward to merge with the coastal upwelled cold water.

During four lunar months in summer 2000 (midJune-mid-October), the internal tides are very weak in amplitude $\left(\eta_{5}\right)$ throughout the UB, in contrast to the usual summer season, when warm deeper stratification accompanies strong internal tides. At the generation region, the internal tide amplitude suddenly decreases during the first 2 months (days 520.5-579.5). While the barotropic tidal currents are essentially the same in all lunar months, the internal tides become weaker when these cold features stably exist, and the thermocline shoals in the UB.

\section{d. Coastal-trapped diurnal internal tides}

The annual average rms amplitude maps of the bandpass-filtered results of $\tau$ for diurnal frequencies are mapped in Fig. 6. The yearly mean maps for both years illustrate the strongest diurnal internal tidal energy all along the southern edge and highest at $36^{\circ} \mathrm{N}, 131^{\circ} \mathrm{E}$.

Because the diurnal internal tides have longer period than the inertial period $(\sim 20 \mathrm{~h})$, they should not be free modes, but rather should be trapped along the shelf edge. The two maps in Fig. 6 exhibit remarkable diurnal internal tides trapped along the continental shelf-slope region. However, there are also high- and low-diurnal internal-tidal energy variations revealed within the basin (e.g., year 1 at $37^{\circ} \mathrm{N}, 131.75^{\circ} \mathrm{E}$ and year 2 at $37^{\circ} \mathrm{N}$, $\left.130.3^{\circ} \mathrm{E}\right)$. These energy variations appear to be related to the mesoscale circulation pattern because high energy is shown near the UWE and low energy is shown near the DCE and the deep trough of the SPF. We examined whether these energy variations may be a standing mode-like offshore structure of the shelf- trapped diurnal internal tides; however neither the temporal envelope nor the phase supports this. We also examined whether some portion of the diurnal internal tidal energy may propagate to the north under an effective Coriolis frequency decreased by negative relative vorticity. However, detailed investigations revealed no significant relations between the diurnal internal tidal energy distribution and mesoscale circulation pattern.

Isoda and Murayama (1993) observed predominantly diurnal tidal currents from current meters moored at $35.20^{\circ}$ and $35.40^{\circ} \mathrm{N}$ along longitude $132^{\circ} \mathrm{E}$. They showed that the cross-shelf current field from the current data corresponds well to the theoretical first-mode interior shelf waves. In their simple numerical model, the coastal-trapped waves originated at the western entrance of the Korea Strait and propagated eastward. They inferred that tidal current forcing in the Korea Strait could generate coastal-trapped waves, because of direct vortex stretching of the water column across the shelf-slope topography. This interpretation of generation is supported by the bottom two panels of Fig. 3, which both exhibit similar spring-neap tidal variations in the diurnal frequency band between $\tau$ (baroclinic) and $P_{\text {bot }}$ (barotropic) records at site P53.

The bottom two panels of Fig. 3 show that the diurnal internal tides at P53 lag the diurnal barotropic tides. The time lag estimated using a cross-correlation analysis is $\sim 2.8$ days. This suggests that the coastal-trapped diurnal internal tides are not locally generated, and their inferred low speed of propagation $\left(<0.3 \mathrm{~m} \mathrm{~s}^{-1}\right)$ may be governed by the shallow water on the shelf. However, the locations of our measurement sites are insufficient to determine the generation region and the propagation direction of the diurnal internal tides. Therefore, our focus in the next two sections returns to the semidiurnal internal tides. 


\section{Generation of internal tides}

In general, internal tides are generated by the interaction of barotropic tidal currents with a sharp change of bottom topography. The continental shelf-slope break is sharp all around the southern UB; however, our horizontal maps of semidiurnal internal tidal energy reveal that internal tides are mainly generated within a restricted region in the western Korea Strait between $130^{\circ}$ and $131^{\circ} \mathrm{E}$.

Recently, Book et al. (2004) reported on the barotropic tidal currents in the Korea Strait using data from moored ADCPs that spanned the Korea Strait assimilated into a tidal model. Their results near $35.5^{\circ} \mathrm{N}$ show that the $M_{2}$ tidal currents in the western Korea Strait $\left(129.5^{\circ}-131^{\circ} \mathrm{E}\right)$ are more than $20 \mathrm{~cm} \mathrm{~s}^{-1}$, while those in the eastern Korea Strait $\left(131^{\circ}-133^{\circ} \mathrm{E}\right)$ are weaker than $5 \mathrm{~cm} \mathrm{~s}^{-1}$. The orientation of the tidal current ellipses is along the axis of the Korea Strait, which is, also important, nearly normal to the shelf break at $130^{\circ}-131^{\circ} \mathrm{E}$. At $132^{\circ} \mathrm{E}$ Isoda and Murayama (1993) measured weak $M_{2}$ and $S_{2}$ tidal currents from current-meter moorings, which is consistent with the tidal-model results of Book et al. (2004). These spatially varying barotropic tidal currents of semidiurnal frequencies over the continental shelf-slope regions account for the semidiurnal internal tide generation being predominantly in a restricted region between $130^{\circ}$ and $131^{\circ} \mathrm{E}$.

According to Baines (1982), internal tide generation is favored where the bottom slope $s$ and the wave characteristics $\gamma$ [Eq. (1)] match. We calculated $s$ from the Korea Strait topography. To calculate $\gamma(z)$ from our PIES observations we estimated the $T, S$, and associated $N(z)$ profiles using the MI-GEM method cited in section 2. These fields were mapped daily in the generation region in order to investigate the temporal variability of the $(s, \gamma)$ matching and compare it with the observed semidiurnal internal tidal energy. The left two panels of Fig. 7 illustrate $s$ at the continental shelf-slope across the Korea Strait, calculated using 2-min-resolution Global Seafloor topography data (Smith and Sandwell 1997). Note that $s$ values of $\sim 0.02$ (boundary between red and orange) occur at depth $\sim 200 \mathrm{~m}$ all across the Korea Strait. The daily time series profiles of the wave characteristics $\gamma$ were estimated using our 2-yr time series profiles of $T(p)$ and $S(p)$ in Eq. (1) with $\omega$ equal to the $M_{2}$ tidal frequency. The upper-right panel of Fig. 7 exhibits the estimated $\gamma$ profiles for the point $\left(35.75^{\circ} \mathrm{N}, 130.5^{\circ} \mathrm{E}\right)$ during the $2 \mathrm{yr}$. High-frequency fluctuations in the time series of $\gamma$ profiles are filtered out using a 15-day low-pass filter.

During much of these two years, the stratification near the shelf slope creates $\gamma$ values of $\sim 0.02$ near depth $200 \mathrm{~m}$ (e.g., days 170-520 and 660-900). The differences between $\gamma$ and mean $s$ of $130.25^{\circ}-130.75^{\circ} \mathrm{E}$ are small $(|\gamma-s|<0.01)$ during these same days, as exhibited in the middle-right panel of Fig. 7. Our observed time series of basin-averaged lunar monthly mean, $\left\langle\eta_{5}\right\rangle$, are energetic during these same days (bottom-right panel of Fig. 7). In contrast, during days 520-660, the $\gamma$ profiles shift significantly shallower. The $\gamma$ values near the shelf slope at $\sim 200 \mathrm{~m}$ change to be $\sim 0.05$, which produces a mismatch with $s$ near the generation region $(|\gamma-s|>0.03)$. This 5-month cold interval corresponds to the time after three strong cold eddies entered the generation region (Mitchell et al. 2005b) and the EKWC diverted into the Offshore Branch (see Fig. 5c). During this interval, the basin-averaged internal tide amplitude $\left\langle\eta_{5}\right\rangle$ decreases by a factor of about 2 as shown in the bottom-right panel of Fig. 7. Consequently, observations confirm that high- or low-amplitude semidiurnal internal tides in the UB are associated with time intervals when the stratification and associated $\gamma$ respectively match or do not match the bottom slope $s$ at the generation region where high barotropic tidal currents exist.

A notable beamlike distribution of semidiurnal internal tides in the UB is consistent with generation along a line source, which is approximated by the shelf break where the barotropic tidal currents flow through the Korea Strait.

\section{Horizontal refraction of internal tides}

We investigate the horizontal refraction of semidiurnal internal tides using a two-dimensional internal wave propagation model (Sherwin et al. 2002). This simple geometric optics model uses the nondispersive speed of the first-mode baroclinic semidiurnal internal tides $\left(C_{1}\right)$ and the velocity field of the mesoscale circulation $\mathbf{U}$ to simulate the propagation of the internal wave fronts. From Eq. (2), we can calculate $C_{1}$ for $\omega$ equal to the $M_{2}$ frequency.

We illustrate in Fig. 8 the resulting $C_{1}$ and $\mathbf{U}$ fields for four lunar months using the monthly mean 3D maps of $T, S$, and $\delta$ in the UB. The monthly mean $C_{1}$ maps have similar structures to the monthly mean $Z_{5}$ circulation patterns shown in Fig. 5 but with additional influence by bathymetry. The $\mathbf{U}$ field in each map is produced by averaging the geostrophic current from 0 to 500 dbar. Results are not highly sensitive to this choice of averaging interval, which approximates the average flow through the thermocline. Within the UWE, $C_{1}$ is faster than in the surrounding regions, and significant horizontal gradients of $C_{1}$ and $\mathbf{U}$ are shown around the strongly developed UWE. The semidiurnal internal tide patterns during these four lunar months (days 

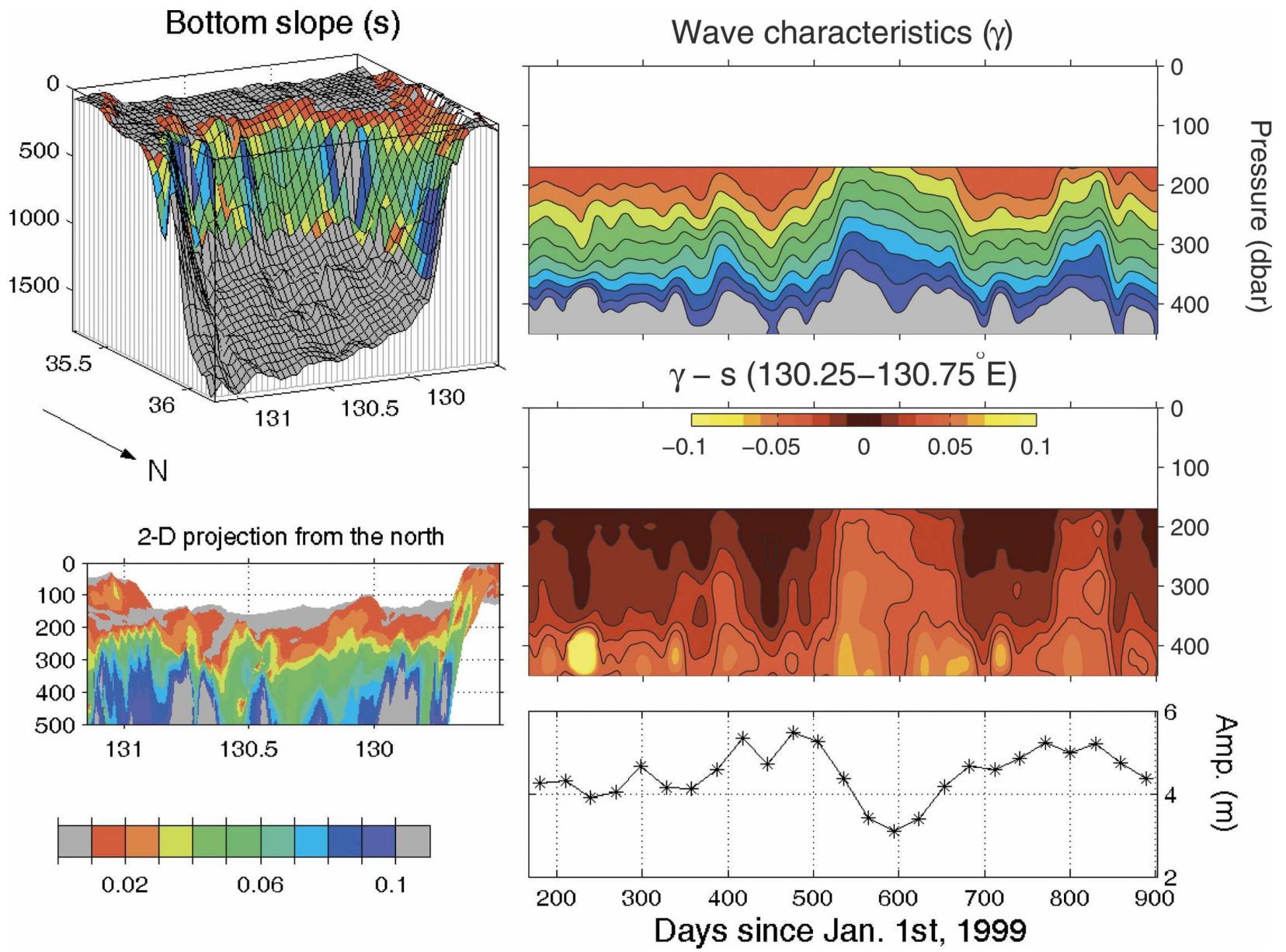

FIG. 7. (left) Bottom slope $(s)$ near the continental shelf-slope region and the two-dimensional projection of $s$ (seen from the north). (top right) Time series profiles of wave characteristics $(\gamma)$ at $35.75^{\circ} \mathrm{N}, 130.5^{\circ} \mathrm{E}$. Both $s$ and $\gamma$ are colored with the same color code. (middle right) Time series profiles of the differences between $\gamma$ and mean $s$ at $130.25^{\circ}-130.75^{\circ} \mathrm{E}$. (bottom right) Time series of basin-average lunar monthly mean $\left\langle\eta_{5}\right\rangle$, computed by averaging all of the 23 PIES values. High (low) values of $\left\langle\eta_{5}\right\rangle$ occur when $s-\gamma$ matching is best (worst).

166.5-196, 255-284.5, 373-402.5, and 520.5-550) can be characterized as straight internal tide beam, significant eastward refraction, westward refraction, and focusing upon a region, respectively (Fig. 5).

The wave front propagation is simulated using these $C_{1}$ and $\mathbf{U}$ fields for each month. The initial wave front, located near the generation region, is assumed to be a straight line with $50-\mathrm{km}$ length. The initial angle of propagation is set to be $10^{\circ}$ clockwise from the north. In this simple 2D internal wave propagation model, the wave front advances by geometric optics in a direction normal to the front by a distance

$$
\Delta d=\Delta t\left(C_{1}+|\mathbf{U}| \cos \varphi\right),
$$

where $\Delta t$ is the time step $(1 \mathrm{~h})$ for computation and $\varphi$ is the angle between $\mathbf{U}$ and the wave propagation direction. At each time step, the wave front is splinesmoothed to avoid wiggles caused by numerical error.
The green and red lines in Fig. 8, superimposed on the $C_{1}$ and $\mathbf{U}$ fields, illustrate the propagating wave fronts and rays simulated in two ways for 2 days. First, the simulation was conducted without including $\mathbf{U}$ in Eq. (5) to isolate the effect of stratification on the refraction (green lines in Fig. 8). Second, the simulation included both $C_{1}$ and $\mathbf{U}$ in Eq. (5) to illustrate the additional effect of current shear (red lines in Fig. 8). In the first simulation (days 166.5-196) without $\mathbf{U}$, the wave fronts propagate northward with a little eastward refraction. When $\mathbf{U}$ is included together with $C_{1}$ in the simulation, the eastward refraction is reduced slightly. The wave front in the second simulation (days 255284.5) without $\mathbf{U}$ spreads because the UWE is in the middle of the wave propagation path. Since $C_{1}$ within the UWE core is faster than that of the surrounding region, the wave front diverges, refracting eastward on the eastern side of the UWE and westward on the west- 

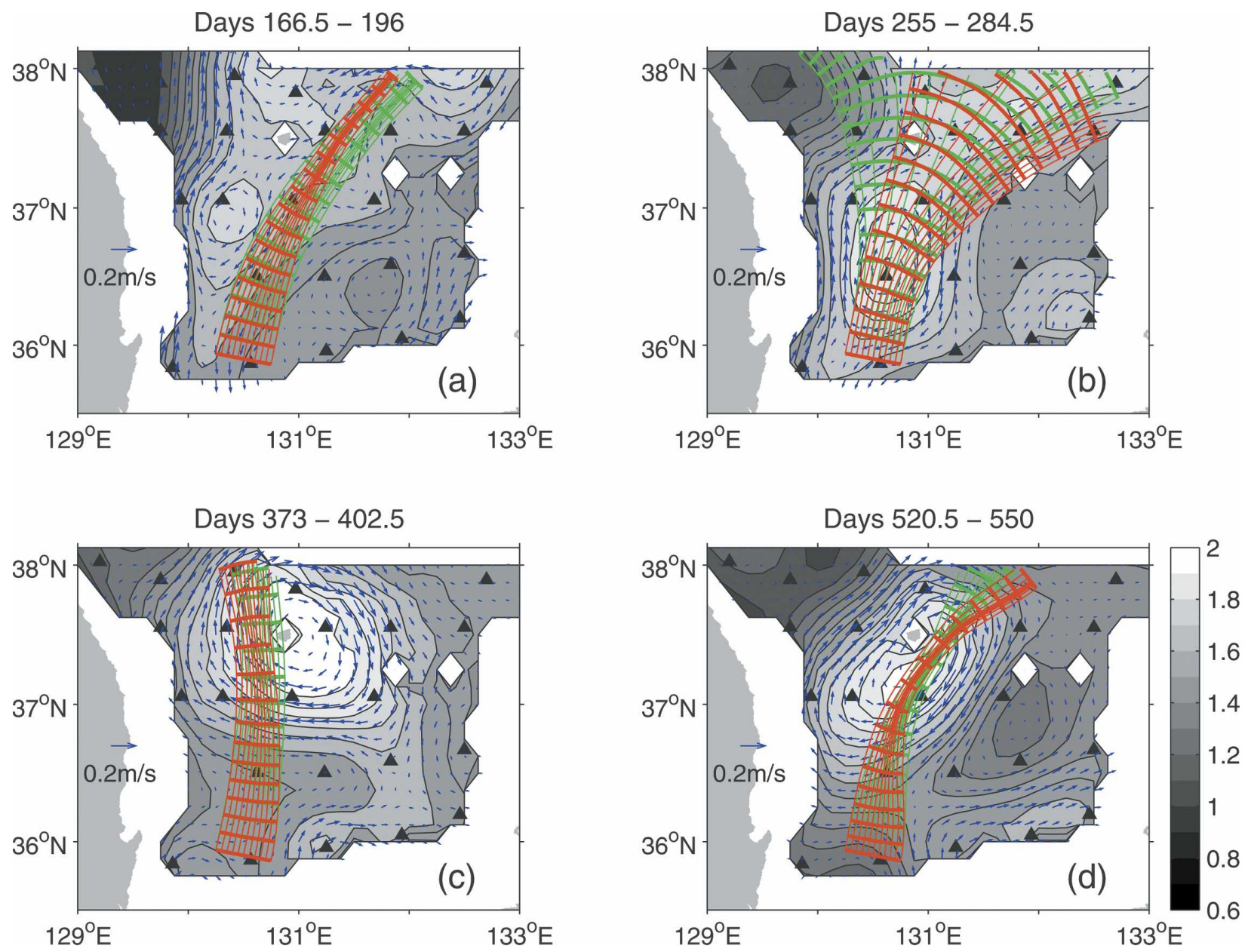

FIG. 8. Lunar monthly mean nondispersive speed of the first baroclinic semidiurnal internal tides $\left(C_{1}\right.$; contour interval $\left.0.1 \mathrm{~m} \mathrm{~s}^{-1}\right)$ and the velocity field of mean upper-level (0-500 dbar) circulation $\mathbf{U}$ during days (a) 166.5-196, (b) 255-284.5, (c) 373-402.5, and (d) 520.5-550. Green and red lines, superimposed on the $C_{1}$ and $\mathbf{U}$ fields, are simulations of wave front propagation, excluding $\mathbf{U}$ and including $\mathbf{U}$, respectively, in a simple two-dimensional wave propagation model. Thick lines are wave fronts drawn every $3 \mathrm{~h}$. Solid triangles indicate PIES sites.

ern side by geometric optics. The simulation with both $C_{1}$ and $\mathbf{U}$ exhibits significant eastward refraction and tends to concentrate the wave energy to the east. The wave front in the third simulation (days 373-402.5) without $\mathbf{U}$ reveals slight westward refraction because the DCE refracts the wave front westward a little and this situates the UWE to be centered to the east of the propagation path. Including $\mathbf{U}$ in the simulation slightly intensifies the westward refraction of wave propagation. In the fourth simulation (days 520.5-550) without $\mathbf{U}$, the wave front focuses upon a narrow region, and then it spreads a little. Including $\mathbf{U}$ in the simulation generates more eastward refraction of wave propagation. This simple wave propagation model for four lunar months captures qualitatively the observed refraction patterns of the internal tide beam that were shown in Fig. 5 and illustrates the essential role of stratification and horizontal shear of currents on them.

\section{Summary}

Internal tides in the UB are observed from the PIES $\tau$ data, vertical round-trip travel time of sound from bottom to surface, collected during 2 yr from June 1999 to June 2001. Horizontal maps of the internal tidal energy distribution are produced by bandpass-filtering analysis of the $\tau$ records to isolate time-dependent variability in the semidiurnal and diurnal frequency bands. Using the first baroclinic mode, the $\tau$ fluctuations are converted to the vertical displacement amplitudes of the thermocline. The yearly and monthly mean maps of rms semidiurnal internal tide amplitude exhibit a beam 
propagating into the open basin from a restricted portion of the shelf-slope break at the north end of the Korea Strait. There are annual and monthly variations of the propagation patterns and generation energy levels that appear to be closely associated with the changes in the mesoscale circulation and stratification. For example, the internal tide beam refracts eastward (westward) when a warm (cold) eddy intersects its path. When a cold eddy invades the generation region, the internal tidal energy at the shelf break near the generation region becomes weaker. In contrast, diurnal internal tides are observed to be trapped along the continental slope region around $36^{\circ} \mathrm{N}$.

The internal tides are generated in the western Korea Strait $\left(35.5^{\circ}-35.7^{\circ} \mathrm{N}, 130^{\circ}-131^{\circ} \mathrm{E}\right)$, where the $M_{2}$ barotropic tidal currents are strong normal to the continental shelf slope, and where the slope of bottom topography matches with the wave characteristics. When the Dok Cold Eddy forms from a deep trough of the SPF and enters this generation region, the thermocline rises and the wave characteristics $(\gamma)$ no longer match the slope $(s)$ of the shelf-slope topography. This may explain an observed twofold weakening of the internal tide amplitude in the UB during this time period.

The refraction of the generated beam of semidiurnal internal tides was explained qualitatively with a simple 2D geometric optics model. Two effects are important, refraction due to horizontal gradients in stratification affecting the first-mode propagation speed $C_{1}$, and refraction due to horizontal shear of the mesoscale current $\mathbf{U}$. Future studies of the generation and propagation of internal tides in the Japan/East Sea could be guided by a full three-dimensional numerical model.

Acknowledgments. We were motivated to investigate the internal-tides signal in our data after viewing internal-tide-model results in the Japan/East Sea presented by Varlamov et al. at the IUGG2003 meeting at Sapporo, Japan. We thank Douglas A. Mitchell and Karen L. Tracey for their great help in processing the PIES data. Thanks are given also to Mark Wimbush and two anonymous reviewers for their useful comments and suggestions on the original manuscript. This work was supported by the Office of Naval Research "Japan/East Sea DRI," including two Basic Research Programs, the Japan/East Sea initiative under Grant N000149810246, and the Naval Research Laboratory's "Linkages of Asian Marginal Seas" under Program Element $0601153 \mathrm{~N}$.

\section{REFERENCES}

Baines, P. G., 1982: On internal tide generation models. Deep-Sea Res., 29, 307-338.
Book, J. W., and Coauthors, 2004: Data assimilation modeling of the barotropic tides in the Korea/Tsushima Strait. J. Oceanogr., 60, 977-993.

Cartwright, D. E., 1982: The tidal signal in inverted echo-sounder records. Deep-Sea Res., 29, 767-784.

Chiswell, S. M., 2002: Energy levels, phase, and amplitude modulation of the baroclinic tide off Hawaii. J. Phys. Oceanogr., 32, 2640-2651.

Dushaw, B. D., P. F. Worcester, B. D. Cornuelle, and B. M. Howe, 1995: Barotropic and baroclinic tides in the central North Pacific Ocean determined from long-range reciprocal acoustic transmissions. J. Phys. Oceanogr., 25, 631-647.

Gill, A. E., 1982: Atmosphere-Ocean Dynamics. Academic Press, $662 \mathrm{pp}$.

Gordon, A. L., G. F. Giulivi, C. M. Lee, H. H. Furey, A. Bower, and L. Talley, 2002: Japan/East Sea intrathermocline eddies. J. Phys. Oceanogr., 32, 1960-1974.

Isoda, Y., and T. Murayama, 1993: Diurnal shelf waves off Hamada on San'in Coast. J. Oceanogr., 49, 71-88.

Kim, C. H., H.-J. Lie, and K.-S. Kim, 1991: On the intermediate water in the southeastern East Sea (Sea of Japan). Oceanography of Asian Marginal Seas, K. Takano, Ed., Elsevier Science, 129-141.

Lee, D.-K., J.-I. Kwon, and S.-B. Hahn, 1998: The wind effect on the cold water formation near Gampo-Ulgi coast. J. Kor. Fish. Soc., 31, 359-371.

Lie, H.-J., C.-W. Shin, and Y. H. Seung, 1992: Internal tidal oscillations of temperature off Jukbyun on the east coast of Korea. J. Oceanol. Soc. Kor., 27, 228-236.

Miropol'sky, Y. Z., 2001: Dynamics of Internal Gravity Waves in the Ocean. Kluwer, 406 pp.

Mitchell, D. A., and Coauthors, 2005a: Upper circulation patterns in the Ulleung Basin. Deep-Sea Res., 52B, 1617-1638.

- W. J. Teague, M. Wimbush, D. R. Watts, and G. G. Sutyrin, 2005b: The Dok cold eddy. J. Phys. Oceanogr., 35, 273-288.

Mitchum, G. T., and S. M. Chiswell, 2000: Coherence of internal tide modulations along the Hawaiian Ridge. J. Geophys. Res., 105, 28 653-28 661.

Munk, W. H., 1981: Internal waves and small scale mixing process. Evolution of Physical Oceanography, B. Warren and C. Wunsch, Eds., The MIT Press, 623 pp.

_ tion. Philos. Trans. Roy. Soc. London, 259A, 533-581.

Park, J.-H., D. R. Watts, K. L. Tracey, and D. A. Mitchell, 2005: A multi-index GEM technique and its application to the southwestern Japan/East Sea. J. Atmos. Oceanic Technol., 22, 1282-1293.

Sherwin, T. J., V. I. Vlasenko, N. Stashchuk, D. R. Gus Jeans, and B. Jones, 2002: Along-slope generation as an explanation for some unusually large internal tides. Deep-Sea Res., 49, 17871799.

Smith, W. H. F., and D. T. Sandwell, 1997: Global seafloor topography from satellite altimetry and ship depth soundings. Science, 277, 1957-1962.

Watts, D. R., and H. T. Rossby, 1977: Measuring dynamic heights with inverted echo sounders: Results from MODE. J. Phys. Oceanogr., 7, 345-358.

—, C. Sun, and S. Rintoul, 2001: A two-dimensional gravest empirical mode determined from hydrographic observations in the subantarctic front. J. Phys. Oceanogr., 31, 2186-2209.

Wunsch, C., 1975: Internal tides in the ocean. Rev. Geophys., 13, 167-182. 